\title{
An Evaluation Model of Quantitative and Qualitative Fuzzy Multi-Criteria Decision-Making Approach for Location Selection of Transshipment Ports
}

\author{
Ji-Feng Ding ${ }^{1}$ and Chien-Chang $\mathrm{Chou}^{2}$ \\ ${ }^{1}$ Department of Aviation and Maritime Transportation Management, Chang Jung Christian University, Gueiren, \\ Tainan 71101, Taiwan \\ ${ }^{2}$ Department of Shipping Technology, National Kaohsiung Marine University, Chi-Chin, Kaohsiung 80543, Taiwan
}

Correspondence should be addressed to Ji-Feng Ding; jfding@mail.cjcu.edu.tw

Received 4 March 2013; Accepted 26 April 2013

Academic Editor: Tsung-Chih Lin

Copyright (C) 2013 J.-F. Ding and C.-C. Chou. This is an open access article distributed under the Creative Commons Attribution License, which permits unrestricted use, distribution, and reproduction in any medium, provided the original work is properly cited.

\begin{abstract}
The role of container logistics centre as home bases for merchandise transportation has become increasingly important. The container carriers need to select a suitable centre location of transshipment port to meet the requirements of container shipping logistics. In the light of this, the main purpose of this paper is to develop a fuzzy multi-criteria decision-making (MCDM) model to evaluate the best selection of transshipment ports for container carriers. At first, some concepts and methods used to develop the proposed model are briefly introduced. The performance values of quantitative and qualitative subcriteria are discussed to evaluate the fuzzy ratings. Then, the ideal and anti-ideal concepts and the modified distance measure method are used in the proposed model. Finally, a step-by-step example is illustrated to study the computational process of the quantitative and qualitative fuzzy MCDM model. The proposed approach has successfully accomplished our goal. In addition, the proposed fuzzy MCDM model can be empirically employed to select the best location of transshipment port for container carriers in the future study.
\end{abstract}

\section{Introduction}

Shipping and port are two major aspects in the sea transport. The issues of shipping and port logistics distribution centres are discussed in the academic literature [1-7] for years. The increasing container transport in liner shipping market has had a vast expansion on the world shipping is growing in importance. In the recent years, due to the blooming development of container shipping in the world, the needs of the transshipment containers in and out of the hub loading centre have been growing rapidly in the Far East. In addition, the governments of Far Eastern countries actively pushed their container ports to become a transshipment centre. Particularly, they engaged in improving computer hardware and software, inland transport systems, and the customs clearance operation and reducing the container handling charges in order to attract more carriers to call their ports as well as to obtain more transshipment quantity of containers to enlarge their port capacity.

The scopes of shipping logistics services [8] are covering forwarding and consolidation services, logistics operations services, value-added services, warehousing and distribution services, intermodal transport services, information technology (IT) solutions, processing of customs clearance, and specialized services. The container port [9] is a nodal point to handle container cargo to offer value-added services such as collection, warehousing, packing, and distribution among international trade and logistics systems. When the huband-spoke network of global container shipping is gradually emerged, the container port in the nodal points has been starting to strengthen its competitive ability to withstand the keen environment. In particular, container transport demands required efficient integrated moves, premium package services, and making the best use of available model 
transport operations and container terminals. Due to the importance of container logistics centres as home bases for merchandise transport, the container carriers need to select a suitable location of a transshipment port to meet the customers' requirements.

Furthermore, because a good location $[2,10]$ will effectively help expand agglomeration economy effects and increase competitive advantages for container ports, as well as the location can help container carriers to be swift the commodities in order to reduce the logistics cost and increase customers' satisfaction. Hence, the container carriers will invest considerable sources for software and hardware facilities subsequently once the location is decided, in which its planning, design, construction, and operation will be also time consuming. In order to satisfy the needs of the container carriers and their customers, there is a need to proceed with a study on the effects from various perspectives and evaluate proper location. Therefore, the location selection of transshipment port for the container carriers is an important issue to study.

The container carriers take many evaluation criteria into consideration while facing the uncertainty environment with keen competition. Due to the quantitative and qualitative characteristics of multiple criteria decision-making (MCDM) [11-15] of location selection of transshipment port and a change in various criteria upon group decision environment, the evaluation problem of location selection of transshipment port is essential to study. Besides, the decision information is hard to come by and is often vague, particularly regarding the linguistic terms. The fuzzy set theory [16] was therefore designed to sort through the uncertainties of vague linguistic terms [17] and helped generate a single possible outcome. Finally, we will propose a quantitative and qualitative fuzzy MCDM method to assist with improving the decision-making quality in this paper.

In summary, the main purpose of this paper is to develop a quantitative and qualitative fuzzy MCDM method to evaluate the problem of location selection of transshipment port for the container carriers. Section 2 presents the research methodologies. The proposed fuzzy MCDM method for evaluating the location of transshipment port is constructed in Section 3. A numerical example is studied in Section 4. Finally, a conclusion is made in the last section.

\section{Research Methodologies}

In this section, some concepts used to develop an integrated fuzzy MCDM method are introduced. These include the triangular fuzzy numbers and algebraic operations, the linguistic values, the graded mean integration representation (GMIR) method, and the modified distance measure approach, respectively.

\subsection{Triangular Fuzzy Numbers and the Algebraic Operations.} In a universe of discourse $X$, a fuzzy subset $A$ of $X$ is defined by a membership function $f_{A}(x)$, which maps each element $x$ in $X$ to a real number in the interval $[0,1]$. The function value $f_{A}(x)$ represents the grade of membership of $x$ in $A$.
A fuzzy number $A$ [18] in real line $\mathfrak{R}$ is a triangular fuzzy number if its membership function $f_{A}: \mathfrak{R} \rightarrow[0,1]$ is as follows

$$
f_{A}(x)= \begin{cases}\frac{(x-l)}{(m-l)}, & l \leq x \leq m \\ \frac{(x-u)}{(m-u),} & m \leq x \leq u \\ 0, & \text { otherwise }\end{cases}
$$

with $-\infty<l \leq m \leq u<\infty$. A triangular fuzzy number can be denoted by $(l, m, u)$.

The triangular fuzzy numbers are easy to use and easy to interpret. The parameter $m$ gives the maximal grade of $f_{A}(x)$; that is, $f_{A}(m)=1$; it is the most probable value of the evaluation data. In addition, "l" and " $u$ " are the lower and upper bounds of the available area for the evaluation data. They are used to reflect the fuzziness of the evaluation data. The narrower the interval $[l, u]$, the lower the fuzziness of the evaluation data.

The Zadeh's extension principle [16] and the Chen's function principle [19] are employed to proceed with the algebraic operations of fuzzy numbers. The merit of the function principle not only does not change the type of membership function of fuzzy number after operations, but also can reduce the troublesomeness and tediousness of operations. Hence, we used the Chen's function principle in this paper. Let $A_{1}=\left(l_{1}, m_{1}, u_{1}\right)$ and $A_{2}=\left(l_{2}, m_{2}, u_{2}\right)$ be fuzzy numbers. The algebraic operations of any two fuzzy numbers $A_{1}$ and $A_{2}$ can be expressed as follows.

(1) Fuzzy Addition. $A_{1} \oplus A_{2}=\left(l_{1}+l_{2}, m_{1}+m_{2}, u_{1}+u_{2}\right)$, where $l_{1}, m_{1}, u_{1}, l_{2}, m_{2}$, and $u_{2}$ are any real numbers.

(2) Fuzzy Multiplication. $A_{1} \otimes A_{2}=\left(l_{1} l_{2}, m_{1} m_{2}, u_{1} u_{2}\right)$, where $l_{1}, m_{1}, u_{1}, l_{2}, m_{2}$, and $u_{2}$ are all nonzero positive real numbers.

(3) Fuzzy Division. (i) $\left(A_{1}\right)^{-1}=\left(l_{1}, m_{1}, u_{1}\right)^{-1}=\left(1 / u_{1}, 1 / m_{1}\right.$, $\left.1 / l_{1}\right)$, where $l_{1}, m_{1}$, and $u_{1}$ are all positive real numbers or all negative real numbers.

(ii) $A_{1} \emptyset A_{2}=\left(l_{1} / u_{2}, m_{1} / m_{2}, u_{1} / l_{2}\right)$, where $l_{1}, m_{1}, u_{1}, l_{2}$, $m_{2}$, and $u_{2}$ are all nonzero positive real numbers.

2.2. Linguistic Values. In fuzzy decision environments, two preference ratings can be used. They are fuzzy numbers and linguistic values (LVs) characterized by fuzzy numbers [17]. Depending on practical needs, decision makers (DMs) may apply one or both of them. In this paper, the weighting set and preference rating set are used to analytically express the LV and describe how important and how good the involved criteria, subcriteria, and alternatives against various subcriteria above the alternative level are.

In this paper, the weighting set is defined as $W=\{\mathrm{VL}, \mathrm{L}$, $\mathrm{M}, \mathrm{H}, \mathrm{VH}\}$ and rating set as $S=\{\mathrm{VP}, \mathrm{P}, \mathrm{F}, \mathrm{G}, \mathrm{VG}\}$; where $\mathrm{VL}=$ Very Low, $\mathrm{L}=$ Low, $\mathrm{M}=$ Medium, $\mathrm{H}=$ High, $\mathrm{VH}=$ Very High, $\mathrm{VP}=$ Very Poor, $\mathrm{P}=$ Poor, $\mathrm{F}=$ Fair, $\mathrm{G}=\mathrm{Good}$, and VG $=$ Very Good. Here, we define the LVs as $\mathrm{VL}=\mathrm{VP}=(0,0,0.2), \mathrm{L}=$ $\mathrm{P}=(0,0.2,0.4), \mathrm{M}=\mathrm{F}=(0.3,0.5,0.7), \mathrm{H}=\mathrm{G}=(0.6,0.8,1)$, and $\mathrm{VH}=\mathrm{VG}=(0.8,1,1)$, respectively. 
2.3. Graded Mean Integration Representation Method. In a fuzzy decision-making environment, a defuzzification method of the triangular fuzzy numbers for ranking the alternatives is essential. To match the fuzzy MCDM method developed in this paper and to solve the problem powerfully, the graded mean integration representation (GMIR) method, proposed by Chen and Hsieh [20], is employed to defuzzify the triangular fuzzy numbers.

Let $A_{i}=\left(l_{i}, m_{i}, u_{i}\right), i=1,2, \ldots, n$, be $n$ triangular fuzzy numbers. By the GMIR method, the GMIR $G\left(A_{i}\right)$ of $A_{i}$ is as follows:

$$
G\left(A_{i}\right)=\frac{l_{i}+4 m_{i}+u_{i}}{6}
$$

Suppose $G\left(A_{i}\right)$ and $G\left(A_{j}\right)$ are the GMIR of the triangular fuzzy numbers $A_{i}$ and $A_{j}$, respectively. We define the following:

$$
\begin{aligned}
& A_{i}>A_{j} \Longleftrightarrow G\left(A_{i}\right)>G\left(A_{j}\right), \\
& A_{i}<A_{j} \Longleftrightarrow G\left(A_{i}\right)<G\left(A_{j}\right), \\
& A_{i}=A_{j} \Longleftrightarrow G\left(A_{i}\right)=G\left(A_{j}\right) .
\end{aligned}
$$

2.4. Modified Distance Measure Approach. Two famous distance measure approaches between two fuzzy numbers, that is, mean and geometrical distance measures, were introduced by Heilpern [21] in 1997. However, Heilpern's method cannot satisfy some special cases between two fuzzy numbers. Hsieh and Chen [22] had proposed the modified geometrical distance approach to improve the drawback of Heilpern's method. To match the integrated fuzzy MCDM method developed in this paper, this modified geometrical distance approach is used to measure the distance of two fuzzy numbers.

Let $A_{i}=\left(l_{i}, m_{i}, u_{i}\right)$ and $A_{j}=\left(l_{j}, m_{j}, u_{j}\right)$ be fuzzy numbers. Then, the Hsieh and Chen's modified geometrical distance can be denoted by the following:

$$
\begin{aligned}
& \operatorname{MD}\left(A_{i}, A_{j}\right) \\
& =\left\{\frac{1}{4}\left[\left(l_{i}-l_{j}\right)^{2}+2\left(m_{i}-m_{j}\right)^{2}+\left(u_{i}-u_{j}\right)^{2}\right]\right\}^{1 / 2} .
\end{aligned}
$$

\section{The Proposed Fuzzy MCDM Method}

A stepwise description of the hybrid fuzzy MCDM method for selecting hub location of transshipment port for the container carriers is proposed in the following.

3.1. Developing a Hierarchical Structure. A hierarchy structure is the framework of system structure. It can not only be utilized to study the interaction among the elements involved in each layer but also help decisionmakers (DMs) to explore the impact of different elements against the evaluated system. The concepts of hierarchical structure analysis with three distinct levels; that is, criteria level, subcriteria level, and alternatives level, are used in this paper. Figure 1 shows the complete hierarchical structure of selecting location of transshipment port with $k$ criteria, $n_{1}+\cdots+n_{t}+\cdots+n_{k}$ subcriteria, and $m$ alternatives.

With regard to the evaluation criteria and subcriteria, the authors referred to some of the literature, which are made known in academic and management publications [2, 10, 23-34]. Finally, six criteria and twenty-nine subcriteria are suggested. Their codes are shown in the parentheses. In this paper, six quantitative subcriteria (i.e., $C_{15}, C_{21}, C_{22}, C_{23}, C_{24}$, and $C_{25}$ ) are negative, whereas three quantitative ones (i.e., $C_{31}, C_{32}$, and $C_{33}$ ) are positive. However the other twenty subcriteria are qualitative and positive.

(1) Geographical condition $\left(C_{1}\right)$. This criterion includes "level of closeness to the import/export area $\left(C_{11}\right)$," "level of proximity of the feeder port $\left(C_{12}\right)$," "level of closeness to main navigation route $\left(C_{13}\right)$," "level of frequency of ship calls $\left(C_{14}\right)$," and "delivery time $\left(C_{15}\right)$."

(2) Cost $\left(C_{2}\right)$. This criterion includes "transportation cost $\left(C_{21}\right)$," "cargo operation cost $\left(C_{22}\right)$," "land cost $\left(C_{23}\right)$," "labour cost $\left(C_{24}\right)$," and "port charges $\left(C_{25}\right)$."

(3) Economy condition $\left(C_{3}\right)$. This criterion includes "volume of import containers $\left(C_{31}\right)$," "volume of export containers $\left(C_{32}\right)$," "volume of transshipment containers $\left(C_{33}\right)$," "level of economic growth $\left(C_{34}\right)$," and "the other trade variables $\left(C_{35}\right)$."

(4) Government, law, and social conditions $\left(C_{4}\right)$. This criterion includes "level of private ownership of enterprise $\left(C_{41}\right)$," "level of efficiency of customs $\left(C_{42}\right)$," "level of efficiency of government department $\left(C_{43}\right)$," and "level of social stability $\left(C_{44}\right)$."

(5) Investment conditions $\left(C_{5}\right)$. This criterion includes "level of tax break and preferential treatment $\left(C_{51}\right)$," "level of law on investment restrictions $\left(C_{52}\right)$," "level of political stability $\left(C_{53}\right)$," "level of land availability and expansion possibility $\left(C_{54}\right)$," and "level of labour quality $\left(C_{55}\right)$."

(6) Infrastructure conditions $\left(C_{6}\right)$. This criterion includes "level of port facilities $\left(C_{61}\right)$," "level of loading and discharging facilities $\left(C_{62}\right)$," "level of intermodal link $\left(C_{63}\right)$," "level of cargo handling efficiency $\left(C_{64}\right)$," and "level of computer information system $\left(C_{65}\right)$."

3.2. Estimation of Fuzzy Weights of All Criteria and Subcriteria. In this paper, the arithmetic mean method is used to obtain the average fuzzy weights of all criteria and subcriteria as well as the fuzzy ratings of alternatives versus all qualitative subcriteria. The LVs of the weighting set and preference rating set, mentioned in the Section 2.2, are assisted in obtaining the fuzzy weights and fuzzy ratings. This is done as follows. 


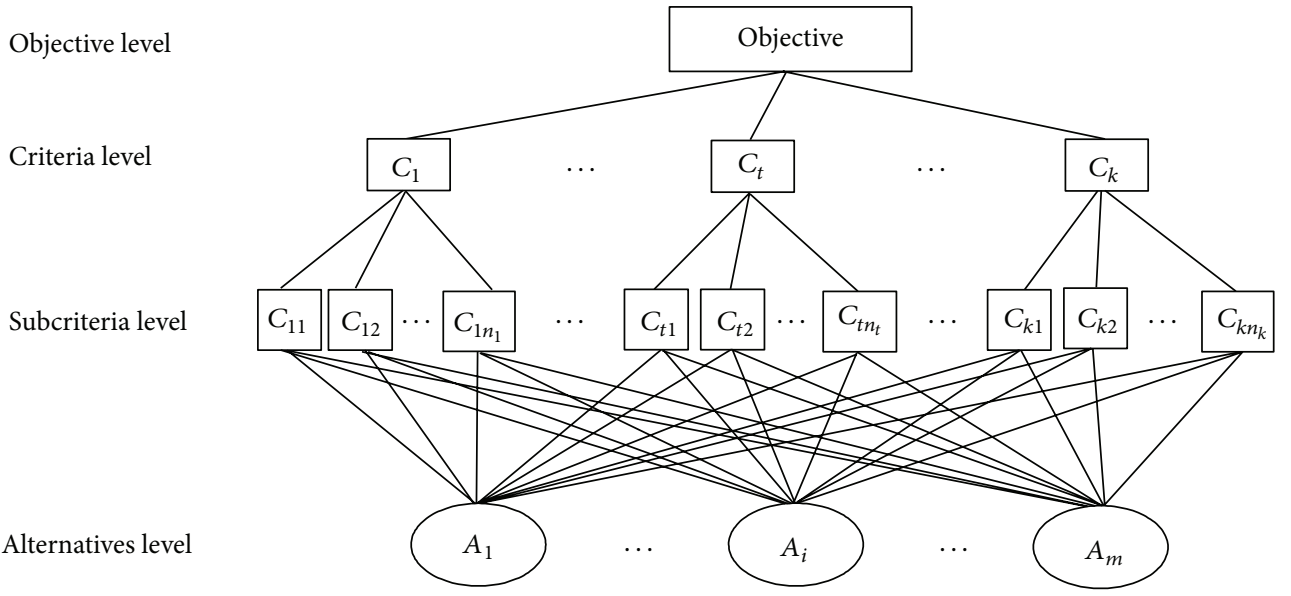

FIGURE 1: The hierarchy structure.

Let $W_{t}^{h}=\left(l_{t}^{h}, m_{t}^{h}, u_{t}^{h}\right), t=1,2, \ldots, k ; h=1,2, \ldots, E$, be the weight given to criterion $C_{t}$ by $h$ th $\mathrm{DM}$. Then, the average fuzzy weight of $C_{t}$ can be represented as follows:

$$
\begin{aligned}
W_{t} & =\frac{1}{E} \otimes\left(W_{t}^{1} \oplus W_{t}^{2} \oplus \cdots \oplus W_{t}^{E}\right) \\
& =\left(l_{t}, m_{t}, u_{t}\right),
\end{aligned}
$$

where $l_{t}=(1 / E) \sum_{h=1}^{E} l_{t}^{h}, m_{t}=(1 / E) \sum_{h=1}^{E} m_{t}^{h}, u_{t}=(1 /$ E) $\sum_{h=1}^{E} u_{t}^{h}$.

Let $W_{t j}^{h}=\left(l_{t j}^{h}, m_{t j}^{h}, u_{t j}^{h}\right), t=1,2, \ldots, k ; j=1,2, \ldots, p_{t}$; $h=1,2, \ldots, E$, be the weight given to subcriterion $\mathrm{SC}_{t j}$ by $h$ th $\mathrm{DM}$. Then, the average fuzzy weight of $\mathrm{SC}_{t j}$ can be represented as follows:

$$
\begin{aligned}
W_{t j} & =\frac{1}{E} \otimes\left(W_{t j}^{1} \oplus W_{t j}^{2} \oplus \cdots \oplus W_{t j}^{\mathrm{E}}\right) \\
& =\left(l_{t j}, m_{t j}, u_{t j}\right),
\end{aligned}
$$

where $l_{t j}=(1 / E) \sum_{h=1}^{E} l_{t j}^{h}, m_{t j}=(1 / E) \sum_{h=1}^{E} m_{t j}^{h}, u_{t j}=(1 /$ E) $\sum_{h=1}^{E} u_{t j}^{h}$.

\subsection{Estimation of Fuzzy Ratings of All Alternatives Versus All} Subcriteria. In this paper, the subcriteria are classified into two categories: (1) the subjective criteria, which have linguistic/qualitative definition, for example, level of closeness to the import/export area; and (2) the objective ones, which are defined in monetary/quantitative terms, for example, delivery time or transport cost.

That is, let $S=\left\{s_{1}, \ldots, s_{t}, \ldots, s_{q}\right\}$ and $O=\left\{o_{1}, \ldots, o_{r}\right.$, $\left.\ldots, o_{p}\right\}$ be the sets of all $q$ qualitative subcriteria and $p$ quantitative ones above the alternatives level. When we measure the fuzzy ratings of all alternatives versus all subcriteria, we face two cases as follows.

Case I (for the qualitative subcriteria). In this paper, the arithmetic mean method is used to obtain the average fuzzy ratings of alternatives versus all qualitative subcriteria. The LVs of the preference rating set, mentioned in the Section 2.2, are assisted in obtaining the fuzzy ratings. This is done as follows.

$$
\text { Let } S_{i t j}^{h}=\left(l_{i t j}^{h}, m_{i t j}^{h}, u_{i t j}^{h}\right), i=1,2, \ldots, m ; t=1,2, \ldots, k \text {; }
$$
$j=1,2, \ldots, p_{t} ; h=1,2, \ldots, E$, be the rating assigned to alternative $A_{i}$ by $h$ th $\mathrm{DM}$ for subcriterion $\mathrm{SC}_{t j}$. Then, the average fuzzy rating of alternative $A_{i}$ can be represented as follows:

$$
\begin{aligned}
S_{i t j} & =\frac{1}{E} \otimes\left(S_{i t j}^{1} \oplus S_{i t j}^{2} \oplus \cdots \oplus S_{i t j}^{E}\right) \\
& =\left(l_{i t j}, m_{i t j}, u_{i t j}\right),
\end{aligned}
$$

where $l_{i t j}=(1 / E) \sum_{h=1}^{E} l_{i t j}^{h}, m_{i t j}=(1 / E) \sum_{h=1}^{E} m_{i t j}^{h}, u_{i t j}=(1 /$ E) $\sum_{h=1}^{E} u_{i t j}^{h}$.

Case II (for the quantitative subcriteria). We use the following method $[35,36]$ to deal with the fuzzy ratings of all alternatives versus all quantitative subcriteria.

(a) When the appropriateness rating of alternative can be estimated effectively in values, the triangular fuzzy numbers can be used directly. For example, if the transport cost per month is about US Dollars 0.65 million, it can be subjectively expressed as $(0.63,0.65$, and 0.68$)$ or $(0.61,0.65$, and 0.67$)$.

(b) If there are historical data, for example, let $t_{1}, t_{2}, \ldots, t_{v}$ represent the transport cost of past $v$ periods, the fuzzy rating of the transport cost can be used the geometric mean method to express the following:

$$
\left(\min _{i}\left\{t_{i}\right\},\left(\prod_{i=1}^{v} t_{i}\right)^{1 / v}, \max _{i}\left\{t_{i}\right\}\right) .
$$

For example, four historical data of the transport cost of alternative $A_{1}$ are $0.63,0.71,0.54$, and 0.69 , then based on (8) mentioned above, the evaluation value can be transformed into triangular fuzzy number as $(0.54,0.639,0.71)$. 
3.4. Calculation of Fuzzy Ideal and Anti-Ideal Solutions. In this paper, the ideal and anti-ideal concepts [37] are used to employ in the proposed fuzzy MCDM algorithm. The logic of ideal and anti-ideal solutions is based on the concept of relative closeness in compliance with the shorter (longer) the distance of alternative $i$ to ideal (anti-ideal), the higher the priority can be ranked.

Firstly, to ensure compatibility between fuzzy ratings of qualitatively positive criteria (or subcriteria) and negative criteria (or subcriteria), the average fuzzy superiority values must be converted to dimensionless indices. The fuzzy ideal values with minimum values in negative subcriteria or maximum values in positive subcriteria should have the maximum rating. Based on the principle stated above, let $S_{i t j}=\left(l_{i t j}, m_{i t j}, u_{i t j}\right)(i=1,2, \ldots, m ; t=1,2, \ldots, k ; j=1,2$, $\ldots, p_{t}$ ) be the average fuzzy rating value of $i$ th alternative under subcriterion $\mathrm{SC}_{t j}$. Let $\delta_{t j}=\max _{i}\left\{u_{i t j}\right\}, \varepsilon_{t j}=\min _{i}\left\{l_{i t j}\right\}$, then the normalized average fuzzy superiority value $\lambda_{i t j}$ of alternative $A_{i}$ for subcriterion $\mathrm{SC}_{t j}$ can be defined as follows.

(1) For the positive subcriterion $\mathrm{SC}_{t j}$ (the subcriteria that have positive contribution to the objective, i.e., benefit subcriterion):

$$
\lambda_{i t j}=\left(x_{i t j}, y_{i t j}, z_{i t j}\right)=\left(\frac{l_{i t j}}{\delta_{t j}}, \frac{m_{i t j}}{\delta_{t j}}, \frac{u_{i t j}}{\delta_{t j}}\right) .
$$

(2) For the negative subcriterion $\mathrm{SC}_{t j}$ (the subcriteria that have negative contribution to the objective, i.e., cost subcriterion):

$$
\lambda_{i t j}=\left(x_{i t j}, y_{i t j}, z_{i t j}\right)=\left(\frac{\varepsilon_{t j}}{u_{i t j}}, \frac{\varepsilon_{t j}}{m_{i t j}}, \frac{\varepsilon_{t j}}{l_{i t j}}\right) .
$$

Then, by using the GMIR method mentioned in Section 2.3, the GMIR value can be express as $G\left(\lambda_{i t j}\right)$. The fuzzy ideal value $\widetilde{I}_{t j}^{+}$and fuzzy anti-ideal value $\widetilde{I}_{t j}^{-}$of each subcriterion above the alternatives layer can be judged and determined by comparing with these GMIR values $G\left(\lambda_{i t j}\right)$. Then,

(1) if $G\left(\lambda_{x t j}\right)=\max _{i} G\left(\lambda_{i t j}\right)$, then the fuzzy ideal value is

$$
\widetilde{I}_{t j}^{+}=\lambda_{x t j}
$$

(2) if $G\left(\lambda_{y t j}\right)=\min _{i} G\left(\lambda_{i t j}\right)$, then the fuzzy anti-ideal value is

$$
\widetilde{I}_{t j}^{-}=\lambda_{y t j}
$$

Finally, we integrate the fuzzy ideal/anti-ideal values into the fuzzy ideal/anti-ideal solutions. Define the fuzzy ideal

\begin{tabular}{|c|c|c|c|}
\hline Criteria/subcriteria & DMs & LVs & Fuzzy weights \\
\hline \multirow{3}{*}{$C_{1}$} & $\mathrm{~A}$ & $\mathrm{M}$ & \multirow{3}{*}{$(0.633,0.833,0.9)$} \\
\hline & B & VH & \\
\hline & $\mathrm{C}$ & VH & \\
\hline \multirow{3}{*}{$C_{2}$} & $\mathrm{~A}$ & $\mathrm{M}$ & \multirow{3}{*}{$(0.5,0.7,0.9)$} \\
\hline & B & $\mathrm{H}$ & \\
\hline & $\mathrm{C}$ & $\mathrm{H}$ & \\
\hline \multirow{3}{*}{$C_{3}$} & $\mathrm{~A}$ & $\mathrm{H}$ & \multirow{3}{*}{$(0.3,0.5,0.7)$} \\
\hline & $\mathrm{B}$ & $\mathrm{L}$ & \\
\hline & $\mathrm{C}$ & $\mathrm{M}$ & \\
\hline \multirow{3}{*}{$C_{4}$} & $\mathrm{~A}$ & $\mathrm{H}$ & \multirow{3}{*}{$(0.5,0.7,0.9)$} \\
\hline & $\mathrm{B}$ & $\mathrm{M}$ & \\
\hline & $\mathrm{C}$ & $\mathrm{H}$ & \\
\hline \multirow{3}{*}{$C_{5}$} & A & $\mathrm{VH}$ & \multirow{3}{*}{$(0.633,0.833,0.9)$} \\
\hline & B & $\mathrm{VH}$ & \\
\hline & $\mathrm{C}$ & $\mathrm{M}$ & \\
\hline \multirow{3}{*}{$C_{6}$} & $\mathrm{~A}$ & $\mathrm{M}$ & \multirow{3}{*}{$(0.467,0.667,0.8)$} \\
\hline & $\mathrm{B}$ & M & \\
\hline & $\mathrm{C}$ & $\mathrm{VH}$ & \\
\hline \multirow{3}{*}{$C_{11}$} & $\mathrm{~A}$ & $\mathrm{H}$ & \multirow{3}{*}{$(0.733,0.933,1)$} \\
\hline & $\mathrm{B}$ & $\mathrm{VH}$ & \\
\hline & $\mathrm{C}$ & $\mathrm{VH}$ & \\
\hline \multirow{3}{*}{$C_{12}$} & A & $\mathrm{L}$ & \multirow{3}{*}{$(0.1,0.3,0.5)$} \\
\hline & $\mathrm{B}$ & $\mathrm{L}$ & \\
\hline & $\mathrm{C}$ & $\mathrm{M}$ & \\
\hline \multirow{3}{*}{$C_{13}$} & $\mathrm{~A}$ & $\mathrm{VH}$ & \multirow{3}{*}{$(0.667,0.867,1)$} \\
\hline & $\mathrm{B}$ & $\mathrm{H}$ & \\
\hline & $\mathrm{C}$ & $\mathrm{H}$ & \\
\hline \multirow{3}{*}{$C_{14}$} & A & M & \multirow{3}{*}{$(0.467,0.667,0.8)$} \\
\hline & $\mathrm{B}$ & M & \\
\hline & $\mathrm{C}$ & $\mathrm{VH}$ & \\
\hline \multirow{3}{*}{$C_{15}$} & A & $\mathrm{H}$ & \\
\hline & B & VH & $(0.733,0.933,1)$ \\
\hline & $\mathrm{C}$ & $\mathrm{VH}$ & \\
\hline & $\mathrm{A}$ & M & \\
\hline$C_{21}$ & $\mathrm{~B}$ & M & $(0.4,0.6,0.8)$ \\
\hline & $\mathrm{C}$ & $\mathrm{H}$ & \\
\hline & $\mathrm{A}$ & $\mathrm{L}$ & \\
\hline$C_{22}$ & B & $\mathrm{H}$ & $(0.2,0.4,0.6)$ \\
\hline & $\mathrm{C}$ & $\mathrm{L}$ & \\
\hline & A & M & \\
\hline$C_{23}$ & $\mathrm{~B}$ & VH & $(0.567,0.767,0.9)$ \\
\hline & $\mathrm{C}$ & $\mathrm{H}$ & \\
\hline & $\mathrm{A}$ & $\mathrm{H}$ & \\
\hline$C_{24}$ & $\mathrm{~B}$ & M & $(0.5,0.7,0.9)$ \\
\hline & $\mathrm{C}$ & $\mathrm{H}$ & \\
\hline & A & $\mathrm{H}$ & \\
\hline$C_{25}$ & $\mathrm{~B}$ & $\mathrm{VH}$ & $(0.733,0.933,1)$ \\
\hline & $\mathrm{C}$ & $\mathrm{VH}$ & \\
\hline & $\mathrm{A}$ & VH & \\
\hline$C_{31}$ & $\mathrm{~B}$ & $\mathrm{VH}$ & $(0.633,0.833,0.9)$ \\
\hline & $\mathrm{C}$ & $\mathrm{M}$ & \\
\hline
\end{tabular}
solution $\widetilde{I}^{+}$and fuzzy anti-ideal solution $\widetilde{I}^{-}$as follows:

$$
\begin{gathered}
\widetilde{I}^{+}=\left(\widetilde{I}_{11}^{+}, \widetilde{I}_{12}^{+}, \ldots, \widetilde{I}_{t 1}^{+}, \ldots, \widetilde{I}_{t p_{t}}^{+}, \ldots,\right. \\
\left.\widetilde{I}_{k 1}^{+}, \ldots, \widetilde{I}_{k p_{k}}^{+}\right), \\
\widetilde{I}^{-}=\left(\widetilde{I}_{11}^{-}, \widetilde{I}_{12}^{-}, \ldots, \widetilde{I}_{t 1}^{-}, \ldots, \widetilde{I}_{t p_{t}}^{-}, \ldots,\right. \\
\left.\widetilde{I}_{k 1}^{-}, \ldots, \widetilde{I}_{k p_{k}}^{-}\right) .
\end{gathered}
$$

TABLE 1: The fuzzy weights of all criteria and subcriteria. 
TABle 1: Continued.

\begin{tabular}{|c|c|c|c|}
\hline Criteria/subcriteria & DMs & LVs & Fuzzy weights \\
\hline \multirow{3}{*}{$C_{32}$} & $\mathrm{~A}$ & $\mathrm{VH}$ & \multirow{3}{*}{$(0.633,0.833,0.9)$} \\
\hline & B & $\mathrm{M}$ & \\
\hline & $\mathrm{C}$ & $\mathrm{VH}$ & \\
\hline \multirow{3}{*}{$C_{33}$} & A & $\mathrm{M}$ & \multirow{3}{*}{$(0.5,0.7,0.9)$} \\
\hline & B & $\mathrm{H}$ & \\
\hline & $\mathrm{C}$ & $\mathrm{H}$ & \\
\hline \multirow{3}{*}{$C_{34}$} & A & $\mathrm{L}$ & \multirow{3}{*}{$(0.2,0.4,0.6)$} \\
\hline & B & $\mathrm{H}$ & \\
\hline & $\mathrm{C}$ & $\mathrm{L}$ & \\
\hline \multirow{3}{*}{$C_{35}$} & A & M & \multirow{3}{*}{$(0.567,0.767,0.9)$} \\
\hline & B & $\mathrm{VH}$ & \\
\hline & $\mathrm{C}$ & $\mathrm{H}$ & \\
\hline \multirow{3}{*}{$C_{41}$} & A & $\mathrm{H}$ & \multirow{3}{*}{$(0.6,0.8,1)$} \\
\hline & B & $\mathrm{H}$ & \\
\hline & $\mathrm{C}$ & $\mathrm{H}$ & \\
\hline \multirow{3}{*}{$C_{42}$} & A & $\mathrm{M}$ & \multirow{3}{*}{$(0.567,0.767,0.9)$} \\
\hline & $\mathrm{B}$ & $\mathrm{H}$ & \\
\hline & $\mathrm{C}$ & $\mathrm{VH}$ & \\
\hline \multirow{3}{*}{$C_{43}$} & A & $\mathrm{VH}$ & \multirow{3}{*}{$(0.467,0.667,0.8)$} \\
\hline & B & $\mathrm{M}$ & \\
\hline & $\mathrm{C}$ & M & \\
\hline \multirow{3}{*}{$C_{44}$} & A & $\mathrm{VH}$ & \multirow{3}{*}{$(0.667,0.867,1)$} \\
\hline & B & $\mathrm{H}$ & \\
\hline & $\mathrm{C}$ & $\mathrm{H}$ & \\
\hline \multirow{3}{*}{$C_{51}$} & A & $\mathrm{H}$ & \multirow{3}{*}{$(0.567,0.767,0.9)$} \\
\hline & B & $\mathrm{VH}$ & \\
\hline & $\mathrm{C}$ & M & \\
\hline \multirow{3}{*}{$C_{52}$} & A & $\mathrm{H}$ & \multirow{3}{*}{$(0.3,0.5,0.7)$} \\
\hline & B & $\mathrm{L}$ & \\
\hline & $\mathrm{C}$ & M & \\
\hline \multirow{3}{*}{$C_{53}$} & A & $\mathrm{VH}$ & \\
\hline & B & $\mathrm{M}$ & $(0.633,0.833,0.9)$ \\
\hline & $\mathrm{C}$ & $\mathrm{VH}$ & \\
\hline & A & $\mathrm{VH}$ & \\
\hline$C_{54}$ & B & $\mathrm{VH}$ & $(0.633,0.833,0.9)$ \\
\hline & $\mathrm{C}$ & $\mathrm{M}$ & \\
\hline & A & $\mathrm{H}$ & \\
\hline$C_{55}$ & B & $\mathrm{H}$ & $(0.6,0.8,1)$ \\
\hline & $\mathrm{C}$ & $\mathrm{H}$ & \\
\hline & A & $\mathrm{H}$ & \\
\hline$C_{61}$ & B & M & $(0.5,0.7,0.9)$ \\
\hline & $\mathrm{C}$ & $\mathrm{H}$ & \\
\hline & A & $\mathrm{H}$ & \\
\hline$C_{62}$ & $\mathrm{~B}$ & $\mathrm{VH}$ & $(0.733,0.933,1)$ \\
\hline & $\mathrm{C}$ & $\mathrm{VH}$ & \\
\hline & A & $\mathrm{H}$ & \\
\hline$C_{63}$ & B & $\mathrm{M}$ & $(0.5,0.7,0.9)$ \\
\hline & $\mathrm{C}$ & $\mathrm{H}$ & \\
\hline & A & $\mathrm{H}$ & \\
\hline$C_{64}$ & B & $\mathrm{VH}$ & $(0.733,0.933,1)$ \\
\hline & $\mathrm{C}$ & $\mathrm{VH}$ & \\
\hline
\end{tabular}

TABLE 1: Continued.

\begin{tabular}{lccc}
\hline Criteria/subcriteria & DMs & LVs & Fuzzy weights \\
\hline \multirow{2}{*}{$C_{65}$} & $\mathrm{~A}$ & $\mathrm{VH}$ & \\
& $\mathrm{B}$ & $\mathrm{H}$ & $(0.667,0.867,1)$ \\
& $\mathrm{C}$ & $\mathrm{H}$ & \\
\hline
\end{tabular}

3.5. Computation of the Distance of Different Alternatives versus the Fuzzy Ideal/Anti-Ideal Solutions. As mentioned in Section 3.2 , let $W_{t}$ and $W_{t j}, t=1,2, \ldots, k ; j=1,2, \ldots, p_{t}$, be the average fuzzy weights of criteria $C_{t}$ and subcriteria $\mathrm{SC}_{t j}$, respectively. Then the normalized integration weights of the subcriteria $\mathrm{SC}_{t j}$ can be obtained by using the GMIR method in Section 2.3, denoted by the following:

$$
\Gamma_{t j}^{*}=\frac{G\left(W_{t}\right)}{\sum_{t=1}^{k} G\left(W_{t}\right)} \times \frac{G\left(W_{t j}\right)}{\sum_{j=1}^{p_{t}} G\left(W_{t j}\right)}, \quad 0 \leq \Gamma_{t j}^{*} \leq 1, \quad \sum \Gamma_{t j}^{*}=1 .
$$

Then, compute the distance of different alternatives versus $\widetilde{I}^{+}$and $\widetilde{I}^{-}$which were denoted by $D_{i}^{+}$and $D_{i}^{-}$, respectively. Define the following:

$$
\begin{array}{r}
D_{i}^{+}=\sqrt{\sum_{t=1}^{k} \sum_{j=1}^{p_{t}}\left[\left(\Gamma_{t j}^{*}\right)^{2} \times\left(\operatorname{MD}\left(\widetilde{I}_{t j}^{+}, \lambda_{i t j}\right)\right)^{2}\right]}, \\
i=1,2, \ldots, m, \\
D_{i}^{-}=\sqrt{\sum_{t=1}^{k} \sum_{j=1}^{p_{t}}\left[\left(\Gamma_{t j}^{*}\right)^{2} \times\left(\operatorname{MD}\left(\widetilde{I}_{t j}^{-}, \lambda_{i t j}\right)\right)^{2}\right]}, \\
i=1,2, \ldots, m,
\end{array}
$$

where $\mathrm{MD}(\cdot)$ can be obtained by using (4) mentioned in Section 2.4.

3.6. Calculation of the Relative Approximation Value of Different Alternatives Versus Ideal Solution and Ranking the Alternatives. The relative approximation value (i.e., the relative closeness) of different alternatives $A_{i}$ versus fuzzy ideal solution $\widetilde{I}^{+}$can be calculated, which can be denoted as follows:

$$
\mathrm{RC}_{i}^{*}=\frac{D_{i}^{-}}{D_{i}^{+}+D_{i}^{-}}, \quad i=1,2, \ldots, m
$$

It is obvious that $0 \leq \mathrm{RC}_{i}^{*} \leq 1, i=1,2, \ldots, m$. Suppose alternative $A_{i}$ is an ideal solution (i.e., $D_{i}^{+}=0$ ), then $\mathrm{RC}_{i}^{*}=1$. Otherwise, if $A_{i}$ is an anti-ideal solution (i.e., $D_{i}^{-}=0$ ), then $\mathrm{RC}_{i}^{*}=0$. The nearer the value $\mathrm{RC}_{i}^{*}$ to 1 , the closer alternative $A_{i}$ comes near the ideal solution. That is, the maximum value of $\mathrm{RC}_{i}^{*}$, then the all alternatives can be ranked. Finally, the best alternative can be selected.

\section{The Numerical Example}

In this section, a numerical example of selecting hub location of transshipment port for a container carrier is illustrated to 
TABLE 2: The original fuzzy ratings of three alternatives versus twenty qualitative/positive subcriteria.

\begin{tabular}{|c|c|c|c|c|c|c|c|}
\hline \multirow{2}{*}{ Subcriteria } & \multirow{2}{*}{ Alternative DM } & \multicolumn{3}{|c|}{ Linguistic values } & \multicolumn{3}{|c|}{ Fuzzy ratings } \\
\hline & & $X$ & $Y$ & $Z$ & $X$ & $Y$ & $Z$ \\
\hline & $\mathrm{A}$ & $\mathrm{P}$ & $\mathrm{G}$ & $\mathrm{P}$ & & & \\
\hline \multirow[t]{3}{*}{$C_{11}$} & $\mathrm{~B}$ & VP & VG & $\mathrm{VP}$ & $(0.1,0.233,0.433)$ & $(0.733,0.933,1)$ & $(0,0.133,0.333)$ \\
\hline & $\mathrm{C}$ & $\mathrm{F}$ & VG & $\mathrm{P}$ & & & \\
\hline & $\mathrm{A}$ & VP & VG & $\mathrm{VP}$ & & & \\
\hline \multirow[t]{3}{*}{$C_{12}$} & $\mathrm{~B}$ & $\mathrm{G}$ & $\mathrm{G}$ & VP & $(0.2,0.267,0.467)$ & $(0.733,0.933,1)$ & $(0,0,0.2)$ \\
\hline & $\mathrm{C}$ & VP & VG & VP & & & \\
\hline & $\mathrm{A}$ & $\mathrm{P}$ & $\mathrm{P}$ & $\mathrm{P}$ & & & \\
\hline \multirow{3}{*}{$C_{13}$} & $\mathrm{~B}$ & G & G & G & $(0.2,0.333,0.533)$ & $(0.2,0.333,0.533)$ & $(0.2,0.333,0.533)$ \\
\hline & $\mathrm{C}$ & VP & VP & VP & & & \\
\hline & $\mathrm{A}$ & $\mathrm{F}$ & $\mathrm{G}$ & $\mathrm{P}$ & & & \\
\hline \multirow[t]{3}{*}{$C_{14}$} & $\mathrm{~B}$ & G & G & $\mathrm{P}$ & $(0.567,0.767,0.9)$ & $(0.667,0.867,1)$ & $(0.267,0.467,0.6)$ \\
\hline & $\mathrm{C}$ & VG & VG & VG & & & \\
\hline & $\mathrm{A}$ & G & $\mathrm{G}$ & $\mathrm{G}$ & & & \\
\hline \multirow{3}{*}{$C_{34}$} & $\mathrm{~B}$ & VG & VG & VG & $(0.467,0.667,0.8)$ & $(0.467,0.667,0.8)$ & $(0.467,0.667,0.8)$ \\
\hline & $\mathrm{C}$ & $\mathrm{P}$ & $\mathrm{P}$ & $\mathrm{P}$ & & & \\
\hline & A & G & VG & $\mathrm{VP}$ & & & \\
\hline \multirow[t]{3}{*}{$C_{35}$} & $\mathrm{~B}$ & G & G & $\mathrm{VP}$ & $(0.4,0.6,0.8)$ & $(0.733,0.933,1)$ & $(0,0.067,0.267)$ \\
\hline & $\mathrm{C}$ & $\mathrm{P}$ & VG & $\mathrm{P}$ & & & \\
\hline & $\mathrm{A}$ & $\mathrm{F}$ & $\mathrm{F}$ & $\mathrm{F}$ & & & \\
\hline \multirow[t]{3}{*}{$C_{41}$} & $\mathrm{~B}$ & $\mathrm{~F}$ & $\mathrm{~F}$ & VP & $(0.3,0.5,0.7)$ & $(0.3,0.5,0.7)$ & $(0.2,0.333,0.533)$ \\
\hline & $\mathrm{C}$ & $\mathrm{F}$ & $\mathrm{F}$ & $\mathrm{F}$ & & & \\
\hline & $\mathrm{A}$ & $\mathrm{P}$ & $\mathrm{P}$ & $\mathrm{P}$ & & & \\
\hline \multirow[t]{3}{*}{$C_{42}$} & $\mathrm{~B}$ & $\mathrm{~F}$ & $\mathrm{~F}$ & $\mathrm{P}$ & $(0.1,0.233,0.433)$ & $(0.367,0.567,0.7)$ & $(0,0.133,0.333)$ \\
\hline & $\mathrm{C}$ & VP & VG & VP & & & \\
\hline & A & $\mathrm{G}$ & G & VP & & & \\
\hline \multirow[t]{3}{*}{$C_{43}$} & $\mathrm{~B}$ & $\mathrm{~F}$ & G & $\mathrm{F}$ & $(0.567,0.767,0.9)$ & $(0.667,0.867,1)$ & $(0.367,0.5,0.633)$ \\
\hline & $\mathrm{C}$ & VG & VG & VG & & & \\
\hline & $\mathrm{A}$ & $\mathrm{F}$ & $\mathrm{G}$ & $\mathrm{F}$ & & & \\
\hline \multirow{3}{*}{$C_{44}$} & $\mathrm{~B}$ & VG & VG & $\mathrm{VP}$ & $(0.567,0.767,0.9)$ & $(0.733,0.933,1)$ & $(0.1,0.233,0.433)$ \\
\hline & $\mathrm{C}$ & $\mathrm{G}$ & VG & $\mathrm{P}$ & & & \\
\hline & $\mathrm{A}$ & VP & VG & $\mathrm{P}$ & & & \\
\hline \multirow{3}{*}{$C_{51}$} & $\mathrm{~B}$ & $\mathrm{~F}$ & $\mathrm{~F}$ & $\mathrm{P}$ & $(0.1,0.167,0.367)$ & $(0.367,0.5,0.633)$ & $(0,0.133,0.333)$ \\
\hline & $\mathrm{C}$ & VP & VP & VP & & & \\
\hline & A & $\mathrm{F}$ & $\mathrm{F}$ & $\mathrm{VP}$ & & & \\
\hline \multirow[t]{3}{*}{$C_{52}$} & $\mathrm{~B}$ & VP & $\mathrm{F}$ & VP & $(0.1,0.233,0.433)$ & $(0.3,0.5,0.7)$ & $(0,0.067,0.267)$ \\
\hline & $\mathrm{C}$ & $\mathrm{P}$ & $\mathrm{F}$ & $\mathrm{P}$ & & & \\
\hline & A & G & G & G & & & \\
\hline \multirow[t]{3}{*}{$C_{53}$} & $\mathrm{~B}$ & VG & VG & $\mathrm{F}$ & $(0.467,0.667,0.8)$ & $(0.467,0.667,0.8)$ & $(0.567,0.767,0.9)$ \\
\hline & $\mathrm{C}$ & $\mathrm{P}$ & $\mathrm{P}$ & VG & & & \\
\hline & A & $\mathrm{P}$ & G & $\mathrm{P}$ & & & \\
\hline \multirow[t]{3}{*}{$C_{54}$} & $\mathrm{~B}$ & VP & VG & $\mathrm{VP}$ & $(0,0.133,0.333)$ & $(0.467,0.667,0.8)$ & $(0,0.133,0.333)$ \\
\hline & $\mathrm{C}$ & $\mathrm{P}$ & $\mathrm{P}$ & $\mathrm{P}$ & & & \\
\hline & $\mathrm{A}$ & G & $\mathrm{P}$ & G & & & \\
\hline \multirow[t]{3}{*}{$C_{55}$} & $\mathrm{~B}$ & VG & VP & VG & $(0.467,0.667,0.8)$ & $(0,0.133,0.333)$ & $(0.467,0.667,0.8)$ \\
\hline & $\mathrm{C}$ & $\mathrm{P}$ & $\mathrm{P}$ & $\mathrm{P}$ & & & \\
\hline & $\mathrm{A}$ & $\mathrm{P}$ & G & G & & & \\
\hline$C_{61}$ & $\mathrm{~B}$ & VP & VG & VG & $(0,0.133,0.333)$ & $(0.467,0.667,0.8)$ & $(0.467,0.667,0.8)$ \\
\hline & $\mathrm{C}$ & $\mathrm{P}$ & $\mathrm{P}$ & $\mathrm{P}$ & & & \\
\hline & $\mathrm{A}$ & $\mathrm{F}$ & $\mathrm{G}$ & $\mathrm{F}$ & & & \\
\hline$C_{62}$ & $\mathrm{~B}$ & VP & VG & VP & $(0.2,0.333,0.533)$ & $(0.467,0.667,0.8)$ & $(0.2,0.333,0.533)$ \\
\hline & $\mathrm{C}$ & $\mathrm{F}$ & $\mathrm{P}$ & $\mathrm{F}$ & & & \\
\hline
\end{tabular}


TABle 2: Continued.

\begin{tabular}{|c|c|c|c|c|c|c|c|}
\hline \multirow{2}{*}{ Subcriteria } & \multirow{2}{*}{ Alternative DM } & \multicolumn{3}{|c|}{ Linguistic values } & \multicolumn{3}{|c|}{ Fuzzy ratings } \\
\hline & & $X$ & $Y$ & $Z$ & $X$ & $Y$ & $Z$ \\
\hline \multirow{3}{*}{$C_{63}$} & $\mathrm{~A}$ & $\mathrm{G}$ & $\mathrm{F}$ & $\mathrm{P}$ & & & \\
\hline & B & VG & VP & VP & $(0.467,0.667,0.8)$ & $(0.2,0.333,0.533)$ & $(0,0.133,0.333)$ \\
\hline & $\mathrm{C}$ & $\mathrm{P}$ & $\mathrm{F}$ & $\mathrm{P}$ & & & \\
\hline \multirow{3}{*}{$C_{64}$} & $\mathrm{~A}$ & G & $\mathrm{F}$ & G & & & \\
\hline & $\mathrm{B}$ & VG & VP & VG & $(0.467,0.667,0.8)$ & $(0.2,0.333,0.533)$ & $(0.467,0.667,0.8)$ \\
\hline & $\mathrm{C}$ & $\mathrm{P}$ & $\mathrm{F}$ & $\mathrm{P}$ & & & \\
\hline \multirow{3}{*}{$C_{65}$} & $\mathrm{~A}$ & G & $\mathrm{P}$ & G & & & \\
\hline & B & VG & VP & VG & $(0.467,0.667,0.8)$ & $(0,0.133,0.333)$ & $(0.467,0.667,0.8)$ \\
\hline & $\mathrm{C}$ & $\mathrm{P}$ & $\mathrm{P}$ & $\mathrm{P}$ & & & \\
\hline
\end{tabular}

TABLE 3: The original fuzzy superiority of three alternatives versus six quantitative/negative subcriteria.

\begin{tabular}{|c|c|c|c|c|c|c|c|}
\hline \multirow{2}{*}{ Subcriteria } & \multicolumn{4}{|c|}{ Original data } & \multicolumn{3}{|c|}{ Fuzzy ratings } \\
\hline & Month & $X$ & $Y$ & $Z$ & $X$ & $Y$ & $Z$ \\
\hline \multirow{4}{*}{$C_{15}$} & January & 3.2 & 3.5 & 3.4 & \multirow{4}{*}{$(2.9,3.07,3.2)$} & \multirow{4}{*}{$(3.1,3.27,3.5)$} & \multirow{4}{*}{$(3.2,3.0,3.4)$} \\
\hline & February & 2.1 & 3.3 & 3.3 & & & \\
\hline & March & 2.9 & 3.2 & 3.3 & & & \\
\hline & April & 3.1 & 3.1 & 3.2 & & & \\
\hline \multirow{4}{*}{$C_{21}$} & January & 189 & 182 & 173 & \multirow{4}{*}{$(178,181.9,189)$} & \multirow{4}{*}{$(181,182.5,184)$} & \multirow{4}{*}{$(173,179.9,190)$} \\
\hline & February & 182 & 181 & 179 & & & \\
\hline & March & 179 & 183 & 178 & & & \\
\hline & April & 178 & 184 & 190 & & & \\
\hline \multirow{4}{*}{$C_{22}$} & January & 75 & 74 & 72 & \multirow{4}{*}{$(72,75.95,79)$} & \multirow{4}{*}{$(74,75.49,78)$} & \multirow{4}{*}{$(71,72.98,75)$} \\
\hline & February & 72 & 75 & 74 & & & \\
\hline & March & 78 & 75 & 75 & & & \\
\hline & April & 79 & 78 & 71 & & & \\
\hline \multirow{4}{*}{$C_{23}$} & January & 1235 & 1211 & 1285 & \multirow{4}{*}{$(1235,1235,1235)$} & \multirow{4}{*}{$(1211,1211,1211)$} & \multirow{4}{*}{$(1285,1285,1285)$} \\
\hline & February & 1235 & 1211 & 1285 & & & \\
\hline & March & 1235 & 1211 & 1285 & & & \\
\hline & April & 1235 & 1211 & 1285 & & & \\
\hline \multirow{4}{*}{$C_{24}$} & January & 23 & 23 & 21 & \multirow{4}{*}{$(23,24.47,26)$} & \multirow{4}{*}{$(23,23.74,25)$} & \multirow{4}{*}{$(20,21.47,23)$} \\
\hline & February & 24 & 23 & 20 & & & \\
\hline & March & 25 & 24 & 23 & & & \\
\hline & April & 26 & 25 & 22 & & & \\
\hline \multirow{4}{*}{$C_{25}$} & January & 11 & 9 & 10 & \multirow{4}{*}{$(8,9.87,12)$} & \multirow{4}{*}{$(7,8.21,9)$} & \multirow{4}{*}{$(9,9.98,11)$} \\
\hline & February & 12 & 8 & 11 & & & \\
\hline & March & 9 & 9 & 10 & & & \\
\hline & April & 8 & 7 & 9 & & & \\
\hline
\end{tabular}

demonstrate the computational process of the proposed fuzzy MCDM model as follows.

Step 1. Assume that a container carrier needs to select a hub location of transshipment port. Three candidate locations $X$, $Y$, and $Z$ are chosen after a preliminary screening for further evaluation. A committee of three DMs (i.e., $A, B$, and $C$ ) is formed to evaluate the best location of transshipment ports among three candidates. Six criteria and twenty-nine subcriteria are suggested in the Section 3.1. It is noted that six quantitative subcriteria (i.e., $C_{15}, C_{21}, C_{22}, C_{23}, C_{24}$, and $C_{25}$ ) are negative, whereas three quantitative ones (i.e., $C_{31}$,
$C_{32}$, and $C_{33}$ ) are positive. The other twenty subcriteria are qualitative and positive.

Step 2. Three DMs use the LVs (mentioned in the Section 2.2) of weighting sets to evaluate the importance weights. Then, according to (5) and (6), the results of the importance weights are shown in Table 1.

Step 3. Evaluate the fuzzy ratings of three alternatives versus all subcriteria. By using the method presented in Section 3.3, the original preference ratings of twenty qualitative/positive subcriteria, the superiority of six quantitative/negative ones 
TABLE 4: The original fuzzy superiority of three alternatives versus three quantitative/positive subcriteria.

\begin{tabular}{|c|c|c|c|c|c|c|c|}
\hline \multirow{2}{*}{ Subcriteria } & \multicolumn{4}{|c|}{ Original data } & \multicolumn{3}{|c|}{ Fuzzy ratings } \\
\hline & Month & $X$ & $Y$ & $Z$ & $X$ & $Y$ & $Z$ \\
\hline \multirow{4}{*}{$C_{31}$} & January & 476 & 460 & 509 & \multirow{4}{*}{$(476,499.3,515)$} & \multirow{4}{*}{$(430,456,470)$} & \multirow{4}{*}{$(508,523.3,545)$} \\
\hline & February & 495 & 470 & 545 & & & \\
\hline & March & 512 & 465 & 508 & & & \\
\hline & April & 515 & 432 & 532 & & & \\
\hline \multirow{4}{*}{$C_{32}$} & January & 871 & 715 & 890 & \multirow{4}{*}{$(865,876.4,892)$} & \multirow{4}{*}{$(715,748.2,763)$} & \multirow{4}{*}{$(890,897.5,912)$} \\
\hline & February & 892 & 763 & 912 & & & \\
\hline & March & 878 & 755 & 893 & & & \\
\hline & April & 865 & 761 & 895 & & & \\
\hline \multirow{4}{*}{$C_{33}$} & January & 325 & 285 & 215 & \multirow{4}{*}{$(312,322.2,327)$} & \multirow{4}{*}{$(265,276.6,285)$} & \multirow{4}{*}{$(215,234.9,251)$} \\
\hline & February & 312 & 276 & 234 & & & \\
\hline & March & 325 & 281 & 251 & & & \\
\hline & April & 327 & 265 & 241 & & & \\
\hline
\end{tabular}

TABLE 5: The NFR and GMIR values of three alternatives versus all subcriteria.

\begin{tabular}{|c|c|c|c|c|c|c|}
\hline \multirow{2}{*}{ Subcriteria } & \multicolumn{2}{|l|}{$X$} & \multicolumn{2}{|l|}{$Y$} & \multicolumn{2}{|l|}{$Z$} \\
\hline & NFR & GMIR & NFR & GMIR & NFR & GMIR \\
\hline$C_{11}$ & $(0.1,0.233,0.433)$ & 0.244 & $(0.733,0.933,1)$ & 0.911 & $(0,0.133,0.333)$ & 0.144 \\
\hline$C_{12}$ & $(0.2,0.267,0.467)$ & 0.289 & $(0.733,0.933,1)$ & 0.911 & $(0,0,0.2)$ & 0.033 \\
\hline$C_{13}$ & $(0.375,0.625,1)$ & 0.646 & $(0.375,0.625,1)$ & 0.646 & $(0.375,0.625,1)$ & 0.646 \\
\hline$C_{14}$ & $(0.567,0.767,0.9)$ & 0.756 & $(0.667,0.867,1)$ & 0.856 & $(0.267,0.467,0.6)$ & 0.456 \\
\hline$C_{15}$ & $(0.906,0.945,1)$ & 0.948 & $(0.829,0.887,0.935)$ & 0.885 & $(0.853,0.967,0.906)$ & 0.938 \\
\hline$C_{21}$ & $(0.915,0.951,0.972)$ & 0.949 & $(0.940,0.948,0.956)$ & 0.948 & $(0.911,0.962,1)$ & 0.960 \\
\hline $\mathrm{C}_{22}$ & $(0.899,0.935,0.986)$ & 0.938 & $(0.910,0.941,0.959)$ & 0.939 & $(0.947,0.973,1)$ & 0.973 \\
\hline$C_{23}$ & $(0.981,0.981,0.981)$ & 0.981 & $(1,1,1)$ & 1 & $(0.942,0.942,0.942)$ & 0.942 \\
\hline $\mathrm{C}_{24}$ & $(0.769,0.817,0.870)$ & 0.818 & $(0.80,0.842,0.870)$ & 0.840 & $(0.870,0.932,1)$ & 0.933 \\
\hline$C_{25}$ & $(0.583,0.709,0.875)$ & 0.716 & $(0.778,0.853,1)$ & 0.865 & $(0.636,0.701,0.778)$ & 0.703 \\
\hline$C_{31}$ & $(0.873,0.916,0.945)$ & 0.914 & $(0.789,0.837,0.862)$ & 0.833 & $(0.932,0.960,1)$ & 0.962 \\
\hline $\mathrm{C}_{32}$ & $(0.948,0.961,0.978)$ & 0.962 & $(0.784,0.820,0.837)$ & 0.817 & $(0.976,0.984,1)$ & 0.985 \\
\hline$C_{33}$ & $(0.954,0.985,1)$ & 0.982 & $(0.810,0.846,0.872)$ & 0.844 & $(0.657,0.718,0.768)$ & 0.716 \\
\hline$C_{34}$ & $(0.584,0.834,1)$ & 0.820 & $(0.584,0.834,1)$ & 0.820 & $(0.584,0.834,1)$ & 0.820 \\
\hline$C_{35}$ & $(0.4,0.6,0.8)$ & 0.60 & $(0.733,0.933,1)$ & 0.911 & $(0,0.067,0.267)$ & 0.089 \\
\hline$C_{41}$ & $(0.429,0.714,1)$ & 0.714 & $(0.429,0.714,1)$ & 0.714 & $(0.286,0.476,0.761)$ & 0.492 \\
\hline$C_{42}$ & $(0.143,0.333,0.619)$ & 0.349 & $(0.524,0.810,1)$ & 0.794 & $(0,0.190,0.476)$ & 0.206 \\
\hline$C_{43}$ & $(0.567,0.767,0.9)$ & 0.756 & $(0.667,0.867,1)$ & 0.856 & $(0.367,0.5,0.633)$ & 0.50 \\
\hline $\mathrm{C}_{44}$ & $(0.567,0.767,0.9)$ & 0.756 & $(0.733,0.933,1)$ & 0.911 & $(0.1,0.233,0.433)$ & 0.244 \\
\hline$C_{51}$ & $(0.158,0.264,0.580)$ & 0.299 & $(0.580,0.790,1)$ & 0.790 & $(0,0.210,0.526)$ & 0.228 \\
\hline$C_{52}$ & $(0.143,0.333,0.619)$ & 0.349 & $(0.429,0.714,1)$ & 0.714 & $(0,0.096,0.381)$ & 0.128 \\
\hline$C_{53}$ & $(0.519,0.741,0.889)$ & 0.729 & $(0.519,0.741,0.889)$ & 0.883 & $(0.630,0.852,1)$ & 0.840 \\
\hline$C_{54}$ & $(0,0.166,0.416)$ & 0.180 & $(0.584,0.834,1)$ & 0.820 & $(0,0.166,0.416)$ & 0.180 \\
\hline$C_{55}$ & $(0.584,0.834,1)$ & 0.820 & $(0,0.166,0.416)$ & 0.180 & $(0.584,0.834,1)$ & 0.820 \\
\hline$C_{61}$ & $(0,0.166,0.416)$ & 0.180 & $(0.584,0.834,1)$ & 0.820 & $(0.584,0.834,1)$ & 0.820 \\
\hline$C_{62}$ & $(0.25,0.416,0.666)$ & 0.430 & $(0.584,0.834,1)$ & 0.820 & $(0.25,0.416,0.666)$ & 0.430 \\
\hline$C_{63}$ & $(0.584,0.834,1)$ & 0.820 & $(0.25,0.416,0.666)$ & 0.430 & $(0,0.166,0.416)$ & 0.180 \\
\hline$C_{64}$ & $(0.584,0.834,1)$ & 0.820 & $(0.25,0.416,0.666)$ & 0.430 & $(0.584,0.834,1)$ & 0.820 \\
\hline$C_{65}$ & $(0.584,0.834,1)$ & 0.820 & $(0,0.166,0.416)$ & 0.180 & $(0.584,0.834,1)$ & 0.820 \\
\hline
\end{tabular}


TABLE 6: The fuzzy ideal and anti-ideal values of all subcriteria.

\begin{tabular}{|c|c|c|}
\hline & Fuzzy ideal values & Fuzzy anti-ideal values \\
\hline$C_{11}$ & $(0.733,0.933,1)$ & $(0,0.133,0.333)$ \\
\hline$C_{12}$ & $(0.733,0.933,1)$ & $(0,0,0.2)$ \\
\hline$C_{13}$ & $(0.375,0.625,1)$ & $(0.375,0.625,1)$ \\
\hline$C_{14}$ & $(0.667,0.867,1)$ & $(0.267,0.467,0.6)$ \\
\hline$C_{15}$ & $(0.906,0.945,1)$ & $(0.829,0.887,0.935)$ \\
\hline$C_{21}$ & $(0.911,0.962,1)$ & $(0.940,0.948,0.956)$ \\
\hline$C_{22}$ & $(0.947,0.973,1)$ & $(0.899,0.935,0.986)$ \\
\hline$C_{23}$ & $(1,1,1)$ & $(0.942,0.942,0.942)$ \\
\hline$C_{24}$ & $(0.870,0.932,1)$ & $(0.769,0.817,0.870)$ \\
\hline$C_{25}$ & $(0.778,0.853,1)$ & $(0.636,0.701,0.778)$ \\
\hline$C_{31}$ & $(0.932,0.960,1)$ & $(0.789,0.837,0.862)$ \\
\hline$C_{32}$ & $(0.976,0.984,1)$ & $(0.784,0.820,0.837)$ \\
\hline$C_{33}$ & $(0.954,0.985,1)$ & $(0.657,0.718,0.768)$ \\
\hline$C_{34}$ & $(0.584,0.834,1)$ & $(0.584,0.834,1)$ \\
\hline$C_{35}$ & $(0.733,0.933,1)$ & $(0,0.067,0.267)$ \\
\hline$C_{41}$ & $(0.429,0.714,1)$ & $(0.286,0.476,0.761)$ \\
\hline$C_{42}$ & $(0.524,0.810,1)$ & $(0,0.190,0.476)$ \\
\hline$C_{43}$ & $(0.667,0.867,1)$ & $(0.367,0.5,0.633)$ \\
\hline$C_{44}$ & $(0.733,0.933,1)$ & $(0.1,0.233,0.433)$ \\
\hline$C_{51}$ & $(0.580,0.790,1)$ & $(0,0.210,0.526)$ \\
\hline$C_{52}$ & $(0.429,0.714,1)$ & $(0,0.096,0.381)$ \\
\hline$C_{53}$ & $(0.519,0.741,0.889)$ & $(0.519,0.741,0.889)$ \\
\hline$C_{54}$ & $(0.584,0.834,1)$ & $(0,0.166,0.416)$ \\
\hline$C_{55}$ & $(0.584,0.834,1)$ & $(0,0.166,0.416)$ \\
\hline$C_{61}$ & $(0.584,0.834,1)$ & $(0,0.166,0.416)$ \\
\hline$C_{62}$ & $(0.584,0.834,1)$ & $(0.25,0.416,0.666)$ \\
\hline$C_{63}$ & $(0.584,0.834,1)$ & $(0,0.166,0.416)$ \\
\hline$C_{64}$ & $(0.584,0.834,1)$ & $(0.25,0.416,0.666)$ \\
\hline$C_{65}$ & $(0.584,0.834,1)$ & $(0,0.166,0.416)$ \\
\hline
\end{tabular}

and of three quantitative/positive ones can be obtained, as shown in Tables 2, 3, and 4, respectively.

Step 4. Calculate the fuzzy ideal solution and anti-ideal solution. At first, the original fuzzy ratings and superiority of all subcriteria must be normalized by using the method presented in Section 3.4. The normalized fuzzy rating (NFR) values above the three alternatives and the GMIR values can be obtained. The results can be shown in Table 5 .

Then, according to Table 5, the fuzzy ideal value $\left(\widetilde{I}_{t j}^{+}\right)$and fuzzy anti-ideal value $\left(\widetilde{I}_{t j}^{-}\right)$can be obtained by comparing with the GMIR values. The results can be shown in Table 6 .

Hence, we can obtain the fuzzy ideal solution $\left(\widetilde{I}^{+}\right)$and fuzzy anti-ideal solution $\left(\widetilde{I}^{-}\right)$; that is,

$$
\begin{aligned}
& \widetilde{I}^{+}=[(0.733,0.933,1),(0.733,0.933,1),(0.375,0.625 \\
& 1), \ldots, \ldots,(0.584,0.834,1),(0.584,0.834,1),(0.584, \\
& 0.834,1)], \text { and } \\
& \widetilde{I}^{-}=[(0,0.133,0.333),(0,0,0.2),(0.375,0.625,1), \ldots, \\
& \ldots,(0,0.166,0.416),(0.25,0.416,0.666),(0,0.166 \\
& 0.416)]
\end{aligned}
$$

TABLE 7: Distance of three alternatives versus fuzzy ideal and antiideal solutions.

\begin{tabular}{lcc}
\hline Candidates & $D_{i}^{+}$ & $D_{i}^{-}$ \\
\hline$X$ & 0.003276528 & 0.002853978 \\
$Y$ & 0.001331147 & 0.006064825 \\
$Z$ & 0.00613908 & 0.001789796 \\
\hline
\end{tabular}

Step 5. Compute the distance of three alternatives versus fuzzy ideal/anti-ideal solutions. Using (14) and (15) proposed in Section 3.5, the results can be shown in Table 7.

Step 6. Calculate the relative closeness value of three alternatives and ranking. Using (16) proposed in Section 3.6, the $\mathrm{RCs}$ of three alternatives are $\mathrm{RC}_{X}^{*}=0.4655, \mathrm{RC}_{Y}^{*}=0.820$, and $\mathrm{RC}_{Z}^{*}=0.2257$.

The ranking order of $\mathrm{RC}_{i}^{*}$ for three alternatives is $Y, X$, and $Z$, respectively. The best location of transshipment port is obviously $Y$. Therefore, the committee shall recommend that transshipment port $Y$ be the most appropriate location for the container carriers based on the proposed fuzzy MCDM model.

\section{Conclusion}

Because the role of container logistics centre as home bases for merchandise transportation has become increasingly important. The container carriers need to select a suitable centre location of transshipment port to meet the requirements of container shipping logistics. The evaluation process of location selection problem of transshipment port involves a multiplicity of complex considerations and poses an MCDM situation. Moreover, some evaluation criteria faced an ambiguous and uncertain nature. Hence, the evaluation of location selection of transshipment port is confronted with a fuzzy decision-making environment. In the light of this, the main purpose of this paper is to develop a hybrid fuzzy MCDM model to evaluate the problem of location selection of transshipment port for the container carriers.

To effectively select best location of transshipment port, a hybrid fuzzy MCDM model is proposed. We develop a hierarchical structure of selecting location of transshipment port with six criteria and twenty-nine subcriteria. The fuzzy weights of all criteria and subcriteria are evaluated. The performance values of quantitative and qualitative subcriteria are discussed to evaluate the fuzzy ratings. Then, the concepts of ideal and anti-ideal solutions are employed in the proposed fuzzy MCDM model. Moreover, Zadeh's linguistic values, Chen and Hsieh's GMIR method, and Hsieh and Chen's modified geometrical distance approach are applied to develop the fuzzy MCDM model. Finally, a step-by-step example is illustrated to study the computational process of the fuzzy MCDM model. In addition, the proposed approach has successfully accomplished our goal. Future study can apply this hybrid fuzzy MCDM model to evaluate the best location selection of transshipment port for container carriers.

In general, the merits of this hybrid fuzzy MCDM model are listed as follows: (1) the quantitative and qualitative subcriteria as well as positive and negative ones are considered in 
this approach; (2) the GMIR method and the modified distance method can improve the quality of this fuzzy ideal and anti-ideal algorithm process; and (3) the proposed model not only releases the limitation of crisp values, but also facilitates its implementation as a computer-based decision support system for prioritizing the best location selection in a fuzzy environment.

\section{Acknowledgment}

The authors would like to thank two anonymous referees for their excellent comments and valuable advice in this paper.

\section{References}

[1] P. M. Alderton, Port Management and Operations, LLP, London, UK, 1999.

[2] C. C. Chou, "An empirical study on port choice behaviors of shippers in a multiple-port region," Marine Technology Society Journal, vol. 43, no. 3, pp. 71-77, 2009.

[3] J. F. Ding and C. C. Chou, "A fuzzy MCDM model of service performance for container ports," Scientific Research and Essays, vol. 6, no. 3, pp. 559-566, 2011.

[4] G. S. Liang, J. F. Ding, and R. E. Chang, "Evaluating key capabilities for International port logistics centers: the application of fuzzy MCDM," Maritime Quarterly, vol. 18, no. 4, pp. 19-44, 2009.

[5] G. S. Liang, J. F. Ding, and C. L. Pan, "Applying fuzzy quality function deployment to evaluate solutions of the service quality for International port logistics centres in Taiwan," Journal of Engineering For the Maritime Environment, vol. 226, no. 4, pp. 387-396, 2012.

[6] C. S. Lu and C. C. Yang, "Comparison of investment preferences for international logistics zones in Kaohsiung, Hong Kong, and Shanghai ports from a Taiwanese manufacturer's perspective," Transportation Journal, vol. 45, no. 1, pp. 30-51, 2006.

[7] A. S. Nir, K. Lin, and G. S. Liang, "Port choice behaviour-from the perspective of the shipper," Maritime Policy and Management, vol. 30, no. 2, pp. 165-173, 2003.

[8] C. S. Lu, "An evaluation of logistics services' requirements of international distribution centers in Taiwan," Transportation Journal, vol. 43, no. 4, pp. 53-66, 2004.

[9] J. F. Ding, "Applying fuzzy quality function deployment (QFD) to identify solutions of service delivery system for port of Kaohsiung," Quality and Quantity, vol. 43, no. 4, pp. 553-570, 2009.

[10] C. C. Chou, "Application of a fuzzy MCDM model to the evaluation of plant location," International Journal of Innovative Computing Information and Control, vol. 6, no. 6, pp. 2581-2594, 2010.

[11] J. H. Cheng and C. H. Tang, "An application of Fuzzy Delphi and Fuzzy AHP for multi-criteria evaluation on bicycle industry supply chains," WSEAS Transactions on Systems and Control, vol. 4, no. 1, pp. 21-34, 2009.

[12] J. F. Ding and G. S. Liang, "Using fuzzy MCDM to select partners of strategic alliances for liner shipping," Information Sciences, vol. 173, no. 1-3, pp. 197-225, 2005.

[13] J. F. Ding, "Fuzzy MCDM approach for selecting strategic partner: an empirical study of a container shipping company in Taiwan," International Journal of Innovative Computing, Information and Control, vol. 5, no. 4, pp. 1055-1068, 2009.
[14] M. A. Hajeeh, "Water desalination plants performance using fuzzy multi-criteria decision making," WSEAS Transactions on Systems, vol. 9, no. 4, pp. 422-431, 2010.

[15] X. Jiang, B. Zheng, and L. Wang, "The coupled method FuzzyAHP applys to solve multi-criteria decision making problems," WSEAS Transactions on Mathematics, vol. 8, no. 11, pp. 657-666, 2009.

[16] L. A. Zadeh, "Fuzzy sets," Information and Control, vol. 8, no. 3, pp. 338-353, 1965.

[17] L. A. Zadeh, "The concept of a linguistic variable and its application to approximate reasoning-I," Information Sciences, vol. 8, no. 3, pp. 199-249, 1975.

[18] D. Dubois and H. Prade, "Operations on fuzzy numbers," International Journal of Systems Science, vol. 9, no. 6, pp. 613626, 1978.

[19] S. Chen and C. Wang, "Fuzzy distance of trapezoidal fuzzy numbers and application," International Journal of Innovative Computing, Information and Control, vol. 4, no. 6, pp. 14451454, 2008.

[20] S. H. Chen and C. H. Hsieh, "Representation, ranking, distance, and similarity of L-R type fuzzy number and application," Australian Journal of Intelligent Information Processing Systems, vol. 6, no. 4, pp. 217-229, 2000.

[21] S. Heilpern, "Representation and application of fuzzy numbers," Fuzzy Sets and Systems, vol. 91, no. 2, pp. 259-268, 1997.

[22] C. H. Hsieh and S. H. Chen, "Model and algorithm of fuzzy product positioning," Information Sciences, vol. 121, no. 1, pp. 61$82,1999$.

[23] C. C. Chou, "An integrated quantitative and qualitative FMCDM model for location choices," Soft Computing, vol. 14, no. 7, pp. 757-771, 2010.

[24] C. C. Chou, "Application of FMCDM model to selecting the hub location in the marine transportation: a case study in southeastern Asia," Mathematical and Computer Modelling, vol. 51, no. 5-6, pp. 791-801, 2010.

[25] K. L. Lee, S. C. Lin, and W. C. Huang, "Identifying the strategies of role transformation for location developing global logistics hub in Asia-Pacific region," International Journal of Logistics Economics and Globalization, vol. 2, no. 1, pp. 51-66, 2009.

[26] K. L. Lee, W. C. Huang, and J. Y. Teng, "Locating the competitive relation of global logistics hub using quantitative SWOT analytical method," Quality and Quantity, vol. 43, no. 1, pp. 87$107,2009$.

[27] J. Y. Teng, K. L. Lee, and W. C. Huang, "A fuzzy multicriterion q-analysis model for international logistic-park location selection," Journal of Marine Science and Technology, vol. 15, no. 2, pp. 89-103, 2007.

[28] S. Gelareh and D. Pisinger, "Fleet deployment, network design and hub location of liner shipping companies," Transportation Research Part E, vol. 47, no. 6, pp. 947-964, 2011.

[29] H. Haralambides, S. Veldman, E. Van Drunen, and M. Liu, "Determinants of a regional port-centric logistics hub: the case of East Africa," Maritime Economics and Logistics, vol. 13, no. 1, pp. 78-97, 2011.

[30] H. S. Nam and D. W. Song, "Defining maritime logistics hub and its implication for container port," Maritime Policy and Management, vol. 38, no. 3, pp. 269-292, 2011.

[31] T. Notteboom, "An application of multi-criteria analysis to the location of a container hub port in South Africa," Maritime Policy and Management, vol. 38, no. 1, pp. 51-79, 2011. 
[32] K. L. Lee, "Analyzing the competitive relations among the location in the Asia-Pacific region for developing the re-export type of global logistics hub," Journal of Marine Science and Technology, vol. 15, no. 3, pp. 187-200, 2007.

[33] K. L. Lee and S. C. Lin, "A fuzzy quantified SWOT procedure for environmental evaluation of an international distribution center," Information Sciences, vol. 178, no. 2, pp. 531-549, 2008.

[34] C. C. Chou, "A combined MCDM and fuzzy mcdm approach to selecting the location of the distribution center in the hub port: an empirical study on hong kong, shanghai and kaohsiung," International Journal of Innovative Computing, Information and Control, vol. 6, no. 7, pp. 3037-3051, 2010.

[35] T. L. Saaty, The Analytic Hierarchy Process, McGraw-Hill, New York, NY, USA, 1980.

[36] G. S. Liang and T. C. Han, "Fuzzy critical path for project network," International Journal of Information and Management Sciences, vol. 15, no. 4, pp. 29-40, 2004.

[37] G. S. Liang, "Fuzzy MCDM based on ideal and anti-ideal concepts," European Journal of Operational Research, vol. 112, no. 3, pp. 682-691, 1999. 


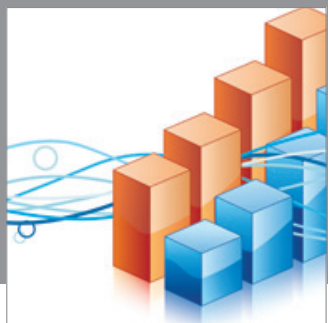

Advances in

Operations Research

mansans

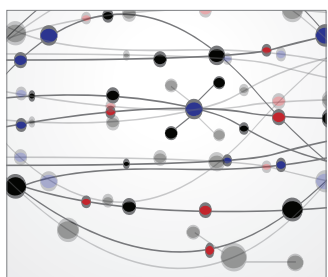

The Scientific World Journal
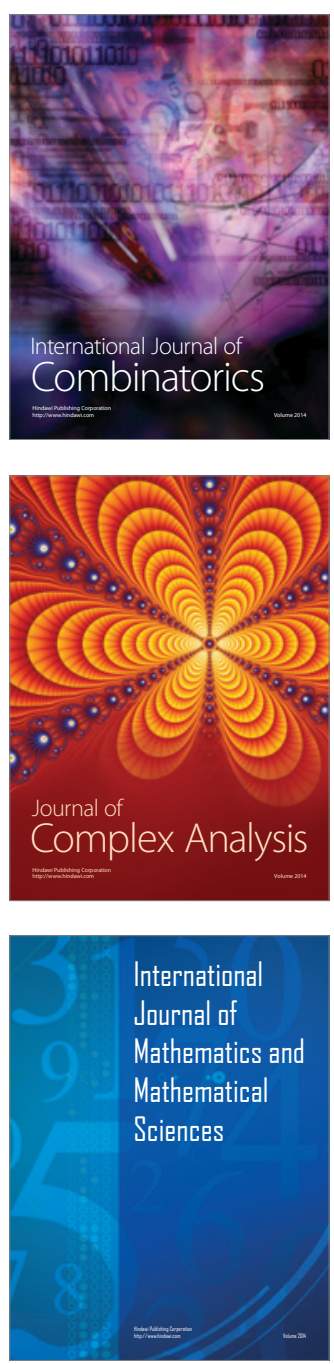
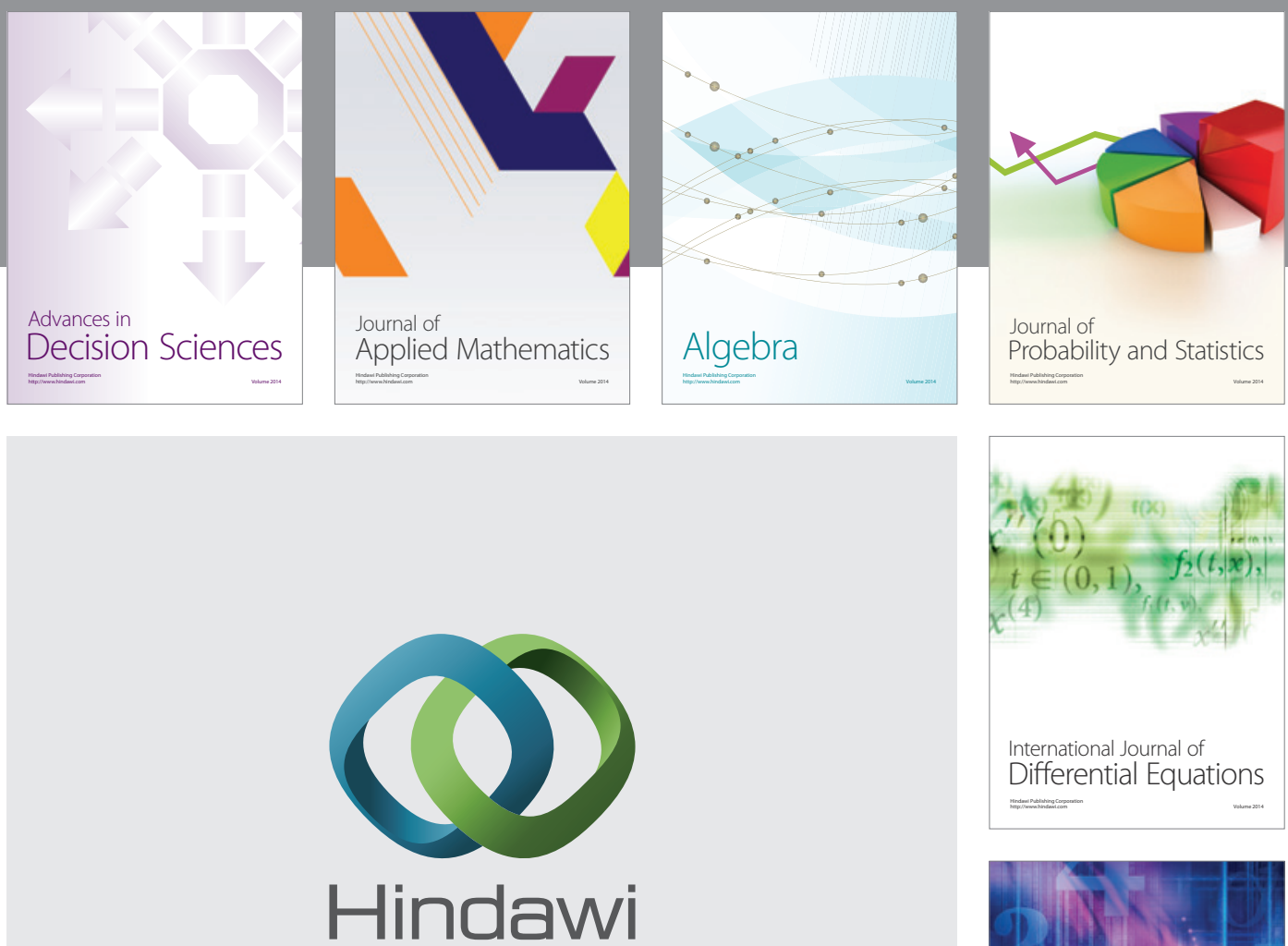

Submit your manuscripts at http://www.hindawi.com
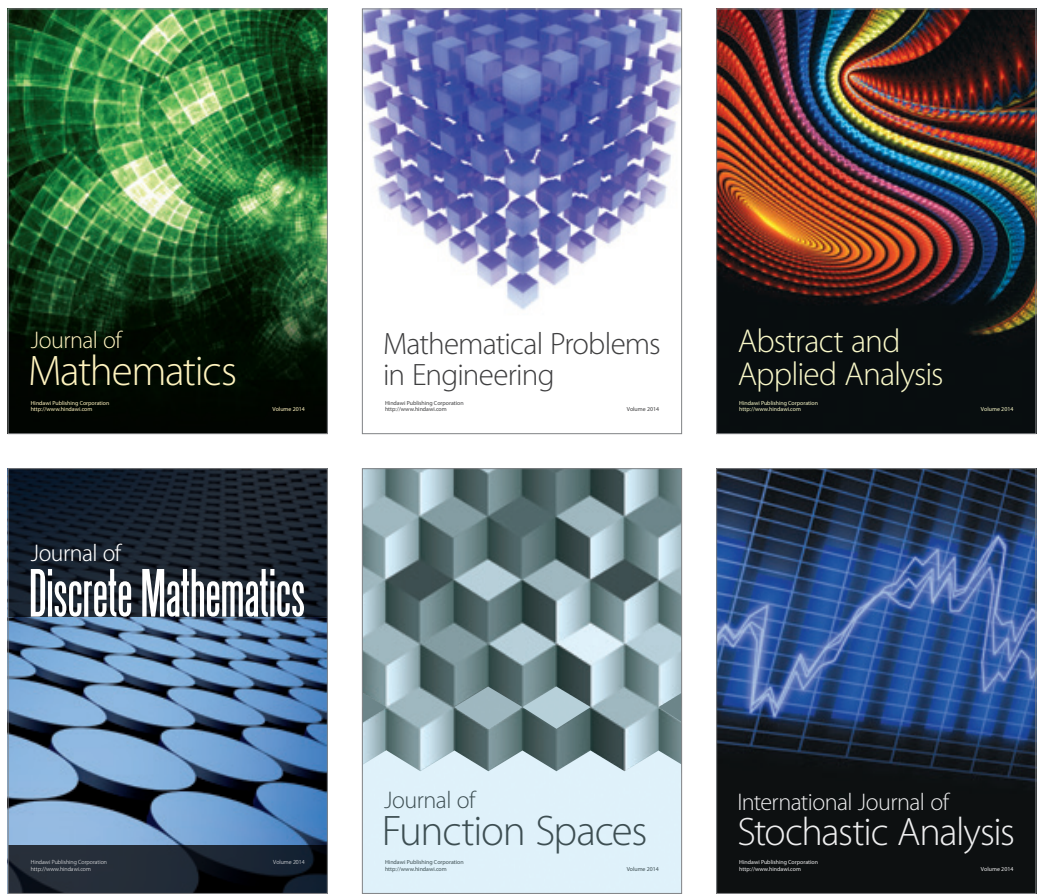

Journal of

Function Spaces

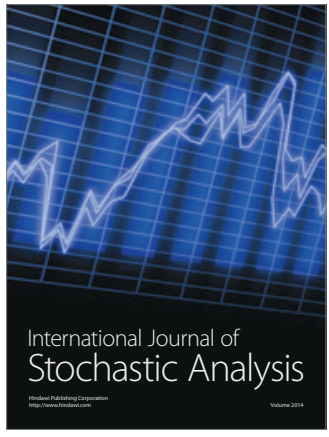

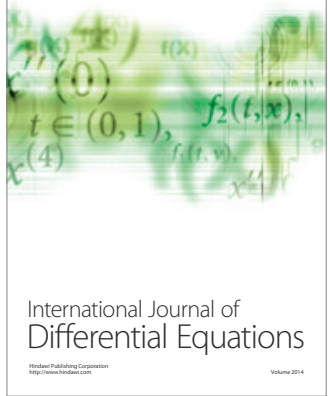
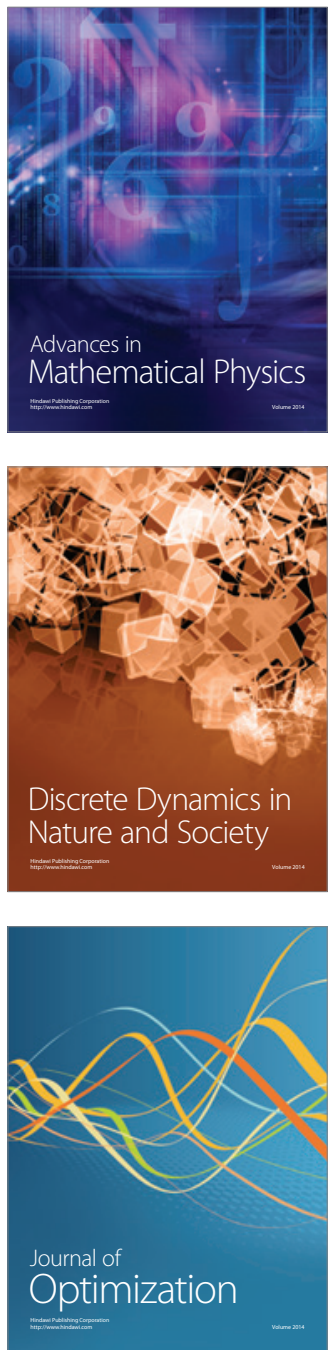